\title{
Nuclear Fuel Cycle and Supply Chain (NFCSC) Technical Monthly December FY-20
}

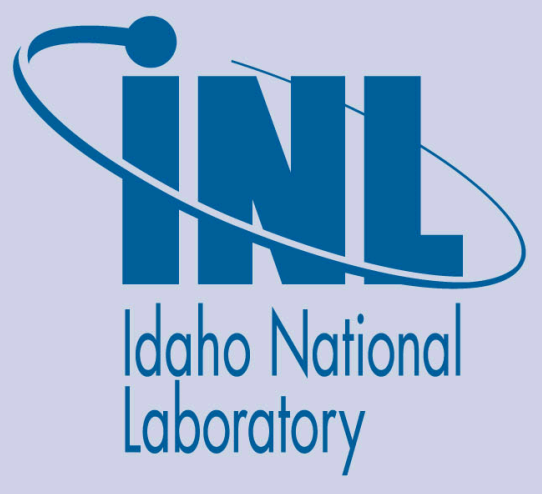

The INL is a U.S. Department of Energy National Laboratory operated by Battelle Energy Alliance 


\section{DISCLAIMER}

This information was prepared as an account of work sponsored by an agency of the U.S. Government. Neither the U.S. Government nor any agency thereof, nor any of their employees, makes any warranty, expressed or implied, or assumes any legal liability or responsibility for the accuracy, completeness, or usefulness, of any information, apparatus, product, or process disclosed, or represents that its use would not infringe privately owned rights. References herein to any specific commercial product, process, or service by trade name, trademark, manufacturer, or otherwise, does not necessarily constitute or imply its endorsement, recommendation, or favoring by the U.S. Government or any agency thereof. The views and opinions of authors expressed herein do not necessarily state or reflect those of the U.S. Government or any agency thereof. 


\section{Nuclear Fuel Cycle and Supply Chain (NFCSC) Technical Monthly December FY-20}

Idaho National Laboratory Idaho Falls, Idaho 83415

http://www.inl.gov

Prepared for the

U.S. Department of Energy

Office of Nuclear Energy

Under DOE Idaho Operations Office

Contract DE-AC07-05ID14517 



\section{CONTENTS}

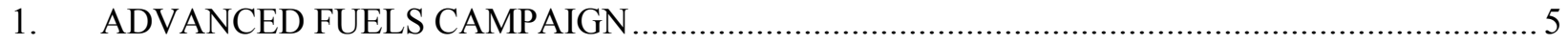

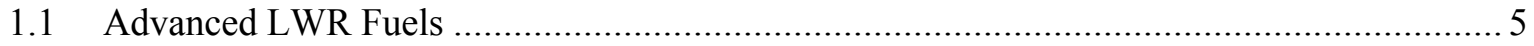

1.1.1 LWR Fuels .........................................................Error! Bookmark not defined.

1.1.2 LWR Core Materials ..................................................Error! Bookmark not defined.

1.1.3 LWR Irradiation Testing \& PIE Techniques ..............Error! Bookmark not defined.

1.1.4 LWR Fuel Safety Testing.........................................Error! Bookmark not defined.

1.2 Advanced Reactor Fuels ......................................................Error! Bookmark not defined.

1.2.1 AR Fuels.................................................................error! Bookmark not defined.

1.2.2 AR Core Materials ..................................................Error! Bookmark not defined.

1.2.3 AR Irradiation Testing \& PIE Techniques .................Error! Bookmark not defined.

1.2.4 AR Fuel Safety Testing...........................................Error! Bookmark not defined.

1.3 Capability Development ......................................................Error! Bookmark not defined.

1.3.1 CX TREAT Testing Infrastructure ...........................Error! Bookmark not defined.

1.3.2 CX Halden Gap Activities.........................................Error! Bookmark not defined.

2. MATERIAL RECOVERY AND WASTE FORMS DEVELOPMENT …............................... 11

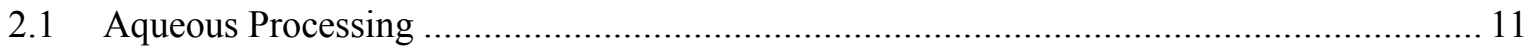

2.2 Advanced Waste Forms and Processes................................Error! Bookmark not defined.

2.2.1 Molten Salt Waste Forms .........................................Error! Bookmark not defined.

2.2.2 Mechanisms and Material Behavior .........................Error! Bookmark not defined.

2.3 Electrochemical/Molten Salt Processing ...............................Error! Bookmark not defined.

2.4 Sigma Team - Off-Gas ....................................................Error! Bookmark not defined.

2.5 Melter Demonstration......................................................Error! Bookmark not defined.

2.6 Material Recovery Pilot Plant ................................................Error! Bookmark not defined.

2.7 Polishing and Solidification (Extraction, Conversion, Downblending) Error! Bookmark not defined.

2.8 Early Design of Engineering Scale Demonstration ................Error! Bookmark not defined.

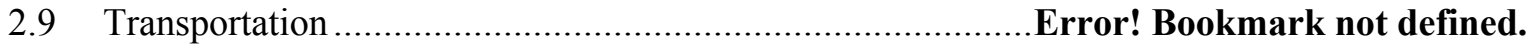

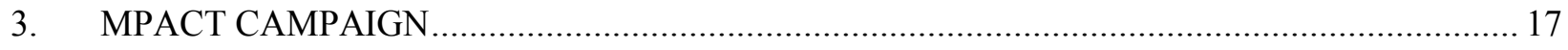

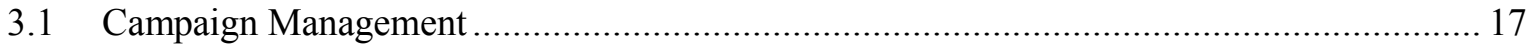

3.1.1 NTD \& Management Support ….................................................................. 17

3.2 MRWFD/Advanced Nuclear Safeguards and Security Research...........Error! Bookmark not defined.

3.2.1 MSR Safeguards ...................................................Error! Bookmark not defined.

3.2.2 Microcalorimetry Consulting .................................Error! Bookmark not defined.

3.3 Safeguards and Security Supporting Technologies - Echem..Error! Bookmark not defined.

3.3.1 Microfluidic Sampler .............................................Error! Bookmark not defined. 
3.3.2 Bubbler for Measuring Density and Depth of Molten Salt ......Error! Bookmark not defined.

3.3.3 OR Voltammetry ....................................................Error! Bookmark not defined.

3.3.4 ER Voltammetry ...................................................Error! Bookmark not defined.

3.4 Safeguards and Security Milestone 2020 - Echem: ................Error! Bookmark not defined.

3.4.1 Advanced Integration Methods................................Error! Bookmark not defined.

3.4.2 Security Facility Models ..........................................Error! Bookmark not defined.

4. SYSTEMS ANALYSIS AND INTEGRATION (SA\&I) CAMPAIGN .................................... 19

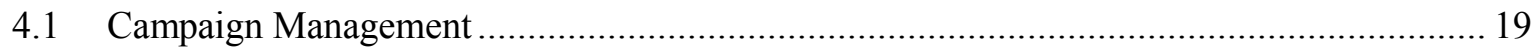

4.2 NUCLEAR ENERGY SYSTEM PERFORMANCE (NESP) Error! Bookmark not defined.

4.2.1 Technology Maturity \& Economic Performance Potential of Micro-reactors .. Error! Bookmark not defined.

4.2.2 Impacts of Foreign Energy Transition Policies ..........Error! Bookmark not defined.

4.2.3 Factors Impacting Nuclear Energy Share...................Error! Bookmark not defined.

4.2.4 Maintain/Update of Fuel Cycle Catalog....................Error! Bookmark not defined.

4.2.5 Transition Analysis Studies and Tools Development Error! Bookmark not defined.

4.2.6 Quick Turn-Around Studies ....................................Error! Bookmark not defined.

4.3 ECONOMIC AND MARKET ANALYSIS FOR NUCLEAR ENERGY SYSTEMS

(EMANES) .........................................................................Error! Bookmark not defined.

4.3.1 Improvement of ACCERT Algorithm .......................Error! Bookmark not defined.

4.3.2 Daily Market Analysis of Load Following and Storage Impacts.... Error! Bookmark not defined.

4.3.3 Cost Basis Report Enhancements .............................Error! Bookmark not defined.

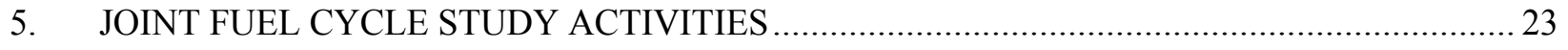

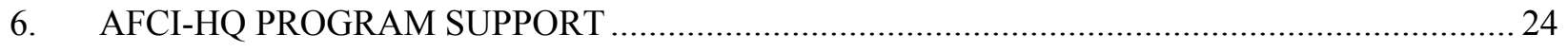

6.1 Innovations in Nuclear Technology R\&D Awards .................................................... 25

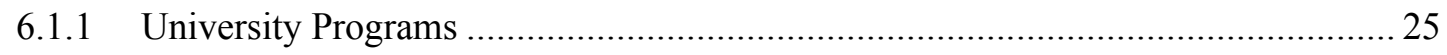

\section{FIGURES}

Figure 1. Images produced from x-ray computed tomography of irradiated UN TRISO particles

from the first MiniFuel target (MF01). Error! Bookmark not defined.

Figure 2. Cs gamma tomography of W01. Error! Bookmark not defined.

Figure 3. Mockup FAST rodlet (lower) and SI (upper) and OA (middle) inner capsules. Error! Bookmark not defined.

Figure 4. Uranium enrichment and forms for advanced reactor concepts. . Error! Bookmark not defined.

Figure 5. Results of PCT conducted with HM glass at different imposed pH values. ..... Error! Bookmark not defined. 


\section{Nuclear Fuel Cycle and Supply Chain (NFCSC) Technical Monthly December FY-20}

\section{ADVANCED FUELS CAMPAIGN}

\subsection{Advanced LWR Fuels}

\subsubsection{LWR Fuels}

[LANL] The latest results on flash sintering of UO2 have been presented at the 2019 MRS Fall meeting in Boston, MA. The results showcased that flash sintering of UO2 can be better controlled when using alternating current and by implementing a current controlled flash regime that minimizes thermal shock. These incremental changes to the flash sintering protocol have resulted in reproducible pellets and have minimized hourglassing while still resulting in high densities within minutes. Further work to reduce porosity is ongoing. (E. Kardoulaki)

\subsubsection{LWR Core Materials}

[LANL] Russ Fawcett of Global Nuclear Fuels was contacted, and welds will be provided on C26M for future small-scale mechanical and ion irradiation testing. Welds will be sent to LANL in January. (S. Maloy)

[LANL] Ring pull tests were performed with digital image correlation on HT-9 in preparation for testing on $\mathrm{FeCrAl}$ alloys. The digital image correlation provides more detailed data on localized strain during the test. It may help with developing improved testing techniques. Data analysis is underway. (S. Maloy)

[INL] The PRW system issue was identified and resolved. (J. Gan)

\subsubsection{LWR Irradiation Testing \& PIE Techniques}

[INL] At the end of December, ATF-2 reached 234 effective full power days and ATF-2B1 (new configuration with general electric boiling water reactor type pins in Tiers 3 and 4) reached 50 effective fuel power days of irradiation. (G. Hoggard)

[INL] Design and analysis efforts to support new ATF-1 scope for Framatome are making progress. Enrichments for the design specifications of the fuel rodlet have been finalized. Conceptual design of the ATF-CC (cladding creep) experiment is on-going. The 166B-1 cycle is on-going, with an anticipated shutdown of 1/10/2020. Preparations for the 168A-1 cycle will commence in January. (C. Murdock)

[INL] The pycnometer and the high precision balance have been installed in the hot cell. The pycnometer system will provide measurements of irradiated fuel density, in order to determine the swelling due to both solid and gaseous fission products as a function of burnup. The pycnometer equipment installed in the hot cell is shown in Figure 1 below. (F. Cappia) 


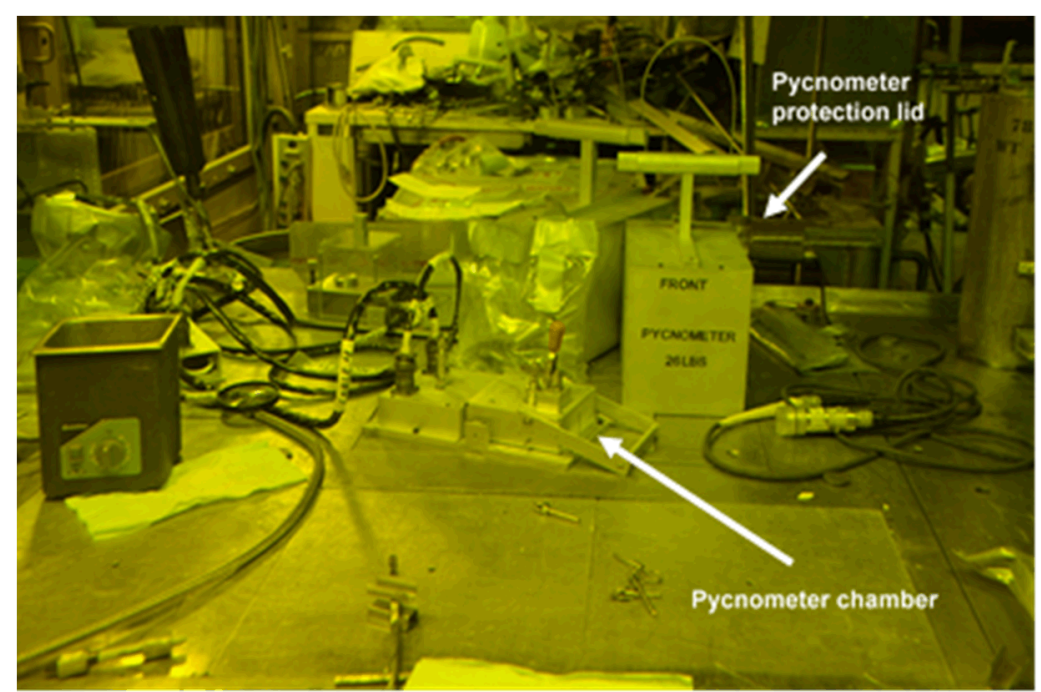

Figure 1. Pycnometer equipment installed in the hot cell.

\subsubsection{LWR Fuel Safety Testing}

\subsubsection{LWR Modeling \& Analysis}

[BNL] A TRACE-Dakota uncertainty/sensitivity analysis for a reactivity-initiated accident (RIA) was successfully run. The insertion of a $1.05 \$$ reactivity in $0.1 \mathrm{~s}$ was modeled in TRACE by using control variables. The calculation selected six sensitivity parameters for a reactor with $\mathrm{UO}_{2}$ fuel and $\mathrm{Zr}$ cladding. Two figures of merit (FOM) of interest were the peak cladding temperature (PCT) and the peak power (Pmax). Using Latin Hypercube sampling 93 parametric cases were executed to provide data for the statistical analysis. The analysis generated cumulative distribution functions (CDF) for the FOMs and their corresponding 95/95 limit values. In addition, response correlations were calculated.
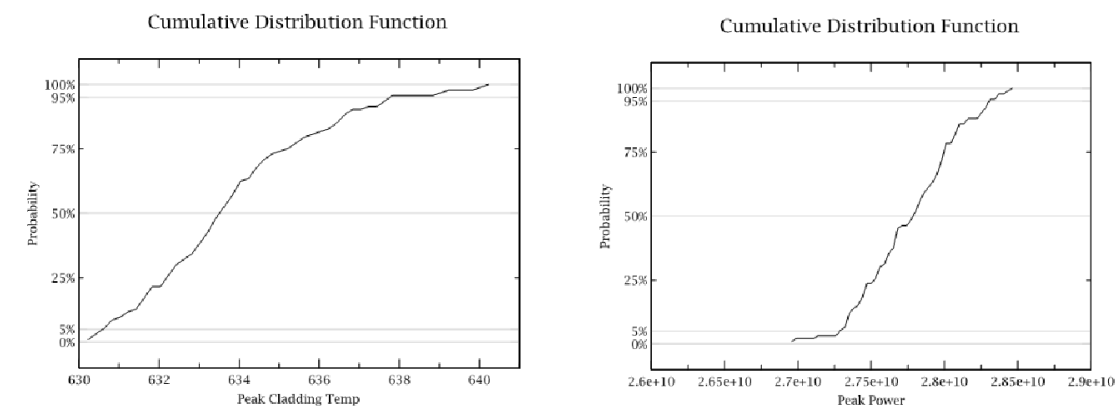

\begin{tabular}{|l|c|c|}
\hline \multicolumn{1}{|c|}{$\begin{array}{c}\text { Sensitivity } \\
\text { Parameter }\end{array}$} & $\begin{array}{c}\text { Partial } \\
\text { (PCT) }\end{array}$ & $\begin{array}{c}\text { Partial } \\
\text { (Pmax) }\end{array}$ \\
\hline Core Power & 0.81099 & 0.998084 \\
\hline $\begin{array}{l}\text { Gap } \\
\text { Conductance }\end{array}$ & -0.728984 & -0.722005 \\
\hline $\begin{array}{l}\text { Fuel Thermal } \\
\text { Conductivity }\end{array}$ & -0.909978 & -0.924435 \\
\hline $\begin{array}{l}\text { Clad Thermal } \\
\text { Conductivity }\end{array}$ & 0.69901 & -0.679706 \\
\hline $\begin{array}{l}\text { Clad Specific } \\
\text { Heat }\end{array}$ & -0.163553 & 0.733008 \\
\hline $\begin{array}{l}\text { Fuel Specific } \\
\text { Heat }\end{array}$ & 0.169163 & 0.9998 \\
\hline
\end{tabular}

The partial response correlation indicates that the fuel specific heat $(\mathrm{Cp})$ has a positive correlation with Pmax. It is consistent with the behavior of fuel responding to negative temperature reactivity effect, a higher $\mathrm{Cp}$ leading to lower temperature rise and smaller negative reactivity resulting in higher transient power. (L.-Y. Cheng)

[BNL] Scoping analyses with FRAPCON continued for full- and half-diameter $\mathrm{UO}_{2}$ pellets in an ATR irradiation capsule. The plan is for the FRAPCON analyses to provide fuel performance related information including fuel temperature distributions, fission gas release, etc. (L.-Y. Cheng, A. Cuadra)

[BNL] Scoping studies continued to estimate the impact on reactor performance and safety characteristics of coating UN fuel pellets to mitigate the fuel/coolant interactions in LWRs. The analyses are being performed with the TRITON lattice code for a detailed model of a reference $17 \times 17$ Westinghouse fuel assembly and the fuel with fully enriched $\mathrm{N}-15$. Approximately fifteen candidates have been proposed by 
LANL for the coating. Initial studies assume $20 \mu \mathrm{m}$ thickness for the coatings applied to the surface of the pellet; fuel pellet outer radius and cladding radii are fixed at the reference values. (M. Todosow)

\subsection{Advanced Reactor Fuels}

\subsubsection{AR Fuels}

[INL] Fabrication has been initiated on the FAST irradiation tests. As previously reported, several legacy HT-9 cladding tubes were down to the size needed for the FAST experiments. Several tubes were also drawn over a solid zirconium rod. The zirconium will be machined to form a zirconium lined cladding tube of the appropriate size for the FAST test. Several assembly procedures were used for these lined tubes. The resulting tube was characterized to determine the best processing parameter. Figure 2 shows a typical example of the two process tubes chosen for machining. As seen, there is a minimal gap between the HT-9 cladding and zirconium rod. The tubing in sample $\mathrm{C}$ was drawn to nearly the final diameter, followed by a normalization heat treatment. After normalization, the zirconium rod was inserted, the assembly reduced through an additional $5 \%$ cold work to the final size, and tempered. Sample D was drawn to nearly the final size, normalized and tempered, then the zirconium rod inserted and the assembly an additional $5 \%$ to the final size. In addition to cladding work, the fuel alloy casting has been initiated. 13 fuel specimens have been alloyed and will be cast to size next month. (R. Fielding)
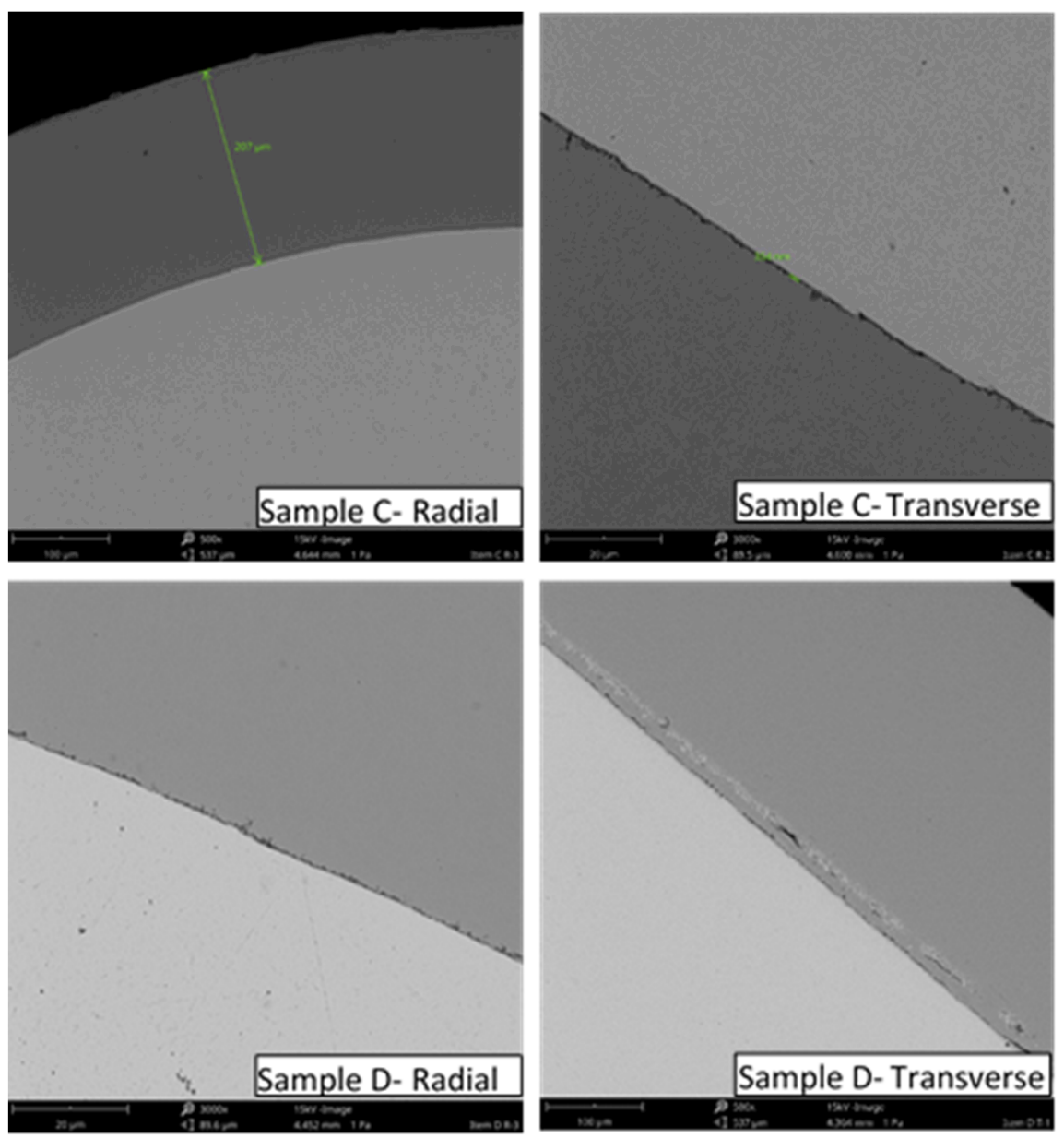

Figure 2. Typical HT-9/Zr interfaces in lined cladding precursor tubes. 
[INL] Additional experiments on the Laser Flash Diffusivity instrument were completed in the thermal property glovebox in IMCL on thermal properties of irradiated metallic fuel. (J. Giglio)

\subsubsection{AR Core Materials}

[ORNL] The 5th cold rolling (CR) by High Precision Tube Rolling (HPTR) of four OFRAC tubes was completed by Nippon Fuel Development (NFD), Japan. The dimensions of the four tubes are $\sim 8.5 \mathrm{~mm}$ outside diameter, $\sim 1.08 \mathrm{~mm}$ wall thickness and lengths ranging from 800 to $927 \mathrm{~mm}$. Following the conclusion of the vacuum annealing study of small samples cut from the end of the four tubes at ORNL, the remaining four tubes were annealed at $850^{\circ} \mathrm{C}$ for 1 hour in vacuum prior to the $6^{\text {th }} \mathrm{CR}$ that will be performed in January 2020. The highlight of this tube fabrication effort is that only 2 CR steps remain for obtaining the final dimension of the thin wall OFRAC tubes, which is $6 \mathrm{~mm}$ outer diameter, $0.5 \mathrm{~mm}$ wall thickness and lengths estimated to be more than $1 \mathrm{~m}$. (Hoelzer/Massey)

[ONRL] The $1 \mathrm{~cm}$ long end sections cut from the $6 \mathrm{SS}-3$ type tensile specimens of 14YWT (PM1 heat) tested in the forced convection sodium (Na) loop at Argonne National Laboratory were mounted edge-on and polished for metallography and SEM analysis. This cross-sectional view permits characterization of the Na composition profile from the surface to the bulk interior of the 14YWT microstructure. A section prepared from the untested control SS-3 tensile specimen was also metallographically prepared. The highlight of this study is understanding the corrosion behavior of 14YWT in molten Na with testing environments representative of Sodium Fast Reactors. (D. Hoelzer)

[ORNL] A presentation on the status of thin wall tubing fabrication efforts of 14YWT and OFRAC and the long-term thermal creep behavior of MA957 was given at the Advanced Fuels Campaign Annual Program Review Meeting at Oregon State University on December 10-12, 2019. (D. Hoelzer)

[PNNL] As part of the program to advance the technology associated with fabricating tubing from difficult-to-fabricate materials, the PNNL rolling mill has been modified so that it can perform pilgering of thick-wall tubes into thin-wall tubes. This capability to pilger thick-wall tubes into finished thin-wall tubing establishes a unique R\&D capability within the DOE complex. Initial pilger runs of both MA956 and 14YWT were preformed successfully last fiscal year resulting in thin-wall tubes about nine inches in length. The objective for this fiscal year is to pilger extended-length thin-wall tubes.

In preparation for an extended length pilger run, thick-wall tubes of both MA956 and 14YWT have been prepared. The dimensions of the thick-wall tubes have been set so that it should be possible to pilger a thin-wall tube between 24 and 36 inches in length. Initial programming of the electronics for the pilger mill was completed in order to set the proper stroke/rotation and acceleration parameters. Following this, initial pilgering runs were performed on both MA956 and 14YWT to obtain the initial reductions toward thin-wall tubes. The longer mandrels and the longer actuator were used for both materials on both initial reduction passes. MA956 was pilgered first and was used for parameter setting prior to pilgering 14YWT. It was found that MA956 is much easier to pilger than 14YWT. Having completed these initial reduction passes, the next series of passes will be undertaken to reduce the two materials to the final thinwall tube dimensions. (R. Omberg)

\subsubsection{AR Irradiation Testing \& PIE Techniques}

[INL] The FAST-1 group of experiments has concluded the final design phase. The final drawings, enrichments, temperature and structural analyses are issued. The final design review has completed and closed out. Fabrication is complete for the outer capsule components. Progress is being made on the inner capsule components and they will be completed in January. Rodlet component fabrication will likely finish in early February. The 166B-1 irradiation cycle is on-going and is anticipated to complete 1/10/2020. Preparations for the 168A-1 irradiation cycle will commence in January. (C. Murdock) 
[INL] The Level 4 milestone titled, "Issue PIE Plan for AFC-FAST," (M4FT- 20IN020303022) was completed. This PIE plan gives guidance of the scope and goals of PIE work to be performed on the future AFC-FAST irradiation experiments. (L. Capriotti)

[INL] Development of Phase I and II Qual Plans continued for the hot cell furnace. (M. Cole)

\subsubsection{AR Fuel Safety Testing}

[ANL] Moderator options for high temperature micro-reactors were explored so as to guide future microreactor fuel cladding development, which include hydrides or beryllium-based moderators. The major issue of using hydrides is its thermal dissociation at high temperature. Thus, it was observed that a reliable enclosure is required for applying hydride materials. For beryllium-based moderators, aside from the fast neutron induced poisoning issue, dimensional changes and the disintegration issue must be mitigated. A composite solution is being investigated with compromise in moderation performance. Other moderator materials may not provide advantageous moderation performance compared to conventional graphite moderator but have the potential to improve other properties with acceptable compromise in moderation performance. Separately, in order to support the FAST fuel irradiation concept that are under development by the AFC campaign, the fuel modeling was started. (T. Kim)

\subsection{Capability Development}

\subsubsection{TREAT Testing Infrastructure}

[INL] Work is continuing on the PTR setup. The new pump laser previously ordered has shipped. Stages for pump laser scanning have been reconfigured for more flexibility. Researcher commitments in other areas may slow progress during January. (R. Schley)

\subsubsection{Halden Gap Activities}

\subsubsection{TREAT}

[INL] Assembly of the ATF-RIA-1-Gamma MARCH-SERTTA capsule was completed and leak checked. The capsule was subsequently delivered to TREAT for pre-irradiation preparation. Experiment Safety Analysis, Supplemental Instructions for TREAT Experiments, and Operations Test Plan were drafted, reviewed, and approved by the Safety Operations Review Committee. (L. Emerson)

[INL] The FAST-1 group of experiments has concluded the final design phase. The final drawings, enrichments, temperature and structural analyses are issued. The final design review has completed and closed out. Fabrication is complete for the outer capsule components. The inner capsule components are making good progress and will finish in January. Rodlet component fabrication will likely finish in early February. The 166B-1 irradiation cycle is on-going and is anticipated to complete 1/10/2020. Preparations for the 168A-1 irradiation cycle will commence in January. (D. Dempsey)

[INL] The experiment execution plan and functions and operations requirements documents were drafted and are in review status. The team continued design iterations based on preliminary feedback from models and hot cell personnel. (L. Emerson)

[INL] Sectioning and mounting of SETH-D and SETH-E rodlets was completed and optical microscopy work commenced. Initial optical microscopy has revealed interesting features in the $\mathrm{Zr}$ fuel interface region including a melt/freeze front, phase change in regions of the $\mathrm{Zr}$ where it melted and refroze, capillary action of molten $\mathrm{Zr}$ penetrating gaps/cracks in the fuel, etc. Additional investigations are underway. (M. Bybee) 
[INL] Experiment support at TREAT continued. The underwater evaluation of pyrometers at HTTL and at TREAT is underway. (T. Pavey)

[INL] A HB Robinson fuel from the HFEF's storage has been retrieved for the cutting activity. A SOW for multiaxial testing has been written; PI (the Utah State University) has reviewed the SOW. The next step is the preparation of contracts from INL and USU sides. A SOW has been drafted for the nano-DIC and micromechanical testing of Cr-coated claddings. An Instron machine has been set in RCB/MFC, and the PIs and HFEFs staff has been trained on the Instron machine. (M. Bybee)

[INL] Hodoscope operations support is being provided at TREAT for experiments. (T. Pavey)

[INL] The draft of the functional requirements for the Sodium Loop Commissioning Test is nearing completion. (T. Smuin)

[INL] Cindi specimens have been loaded into capsules and are ready for shipment to TREAT. (T. Smuin)

[INL] HFEF has initiated the process of can cutting procedures and training which will aid in the retrieval of fuel from RSWF. (M. Bybee)

[INL] Design efforts continued on the necessary tooling and fixtures to perform remote handling of the MARCH-SERTTA experiment device. A flow path was developed for handling operations and used as the basis to begin a safety assessment of the activities to review against the safety basis of HFEF. Development of a data acquisition and control system to support performing instrumentation checks during assembly of the experiment vehicle prior to shipping from HFEF to TREAT is needed. (M. Bybee)

[INL] The draft modeling and system designs for the end cap welding system was completed. The design review of the end cap welding system was completed. (M. Cole)

[INL] The flow testing rig was modified to reduce the bypass flow around the basket. Flow testing will resume next month. Closure Plate drawings and requirements are being finalized. The procurement process for the new closure plate was initiated. Design work has continued on the booster element baskets and the In-Pile Tubes. (T. Maddock)

For more information on Fuels contact Steven Hayes (208) 526-7255. 


\section{MATERIAL RECOVERY AND WASTE FORMS DEVELOPMENT}

\subsection{Aqueous Processing}

[INL] The INL radiolysis test loop is comprised of the solvent radiolysis loop and the solvent reconditioning loop. The INL test loop was originally designed, assembled, and commissioned during FY-09. During the intervening ten years, several different hydrometallurgical processes have been evaluated using the system. These tests have resulted in corrosion and normal wear and tear on components of the radiolysis loop and the reconditioning loop. In addition, the decay of the ${ }^{60} \mathrm{Co}$ special form sources contained within the gamma irradiator has resulted in a dramatic decrease in effective gamma dose rate. Due to these reasons, the INL was tasked with re-designing the test loop system. During the first quarter of FY-20, the test loop design was optimized in order to maximize the effective gamma dose rate. A new test loop apparatus has been constructed and testing of the new apparatus is ongoing. The main improvement implemented with the new test loop design is the elimination of loop components located outside of the gamma irradiator sample chamber. No changes to the reconditioning section of the INL radiolysis test loop have been proposed. (D. Wood)

[ONRL] Vyacheslav (Slava) Bryantsev was invited to present his work at International Workshop on Theory Frontiers in Actinide Sciences: Chemistry and Materials, Santa Fe, New Mexico, USA, Feb 2- 5, 2020. A summary is included below:

Title: Do we really understand the origin of selectivity for differentiation of trivalent actinides from lanthanides?
Abstract: There is a notion that efficient differentiation of trivalent actinides from lanthanides is due to the presence of soft donor atoms that interact more strongly with actinides than lanthanides because of greater spatial extension of $5 \mathrm{f}$ orbitals relative to $4 \mathrm{f}$ orbitals. While many theoretical concepts have been explored to elucidate ligand selectivity for actinides over lanthanides, there still remains a gap in understanding the origin of this effect, which hampers progress in guiding the design of more selective ligands using computational tools. In this work, we employ theoretical calculations to rationalize $\mathrm{Am}(\mathrm{III})$ over $\mathrm{Eu}(\mathrm{III})$ and $\mathrm{Nd}$ (III) selectivity for a series of recently synthesized and characterized aminopolycarboxylic acids having the same total charge and denticity. These features of the ligands allowed us to focus on electronic energy differences and compare the performance of several density functionals, including general gradient approximation (GGA), meta-GGA, and hybrid functionals. The results reveal several deficiencies of density functionals to reproduce the magnitude and selectivity trends, demonstrating limitations of the orbital and electron density analysis of chemical bonding based on one-electron theory methods. Therefore, the origin of trivalent actinide versus lanthanide selectivity is discussed in the framework of the many-body electron theory.

[ORNL] The optimization of conditions for the reaction between ethyl L-(-)-lactate and ethyl 2bromopropionate in the presence of $\mathrm{NaH}$ has been completed. Addition of extra equivalent of base $(\mathrm{NaH}$ or LiOEt) leads to nearly complete conversion of $(S, S)$ isomer into the desirable $(R, S)$-isomer. Lesser amounts of additional base result in incomplete conversion of $(S, S)$-isomer (use of extra 0.5 eq of $\mathrm{NaH}$ resulted in $6: 1$ $(R, S):(S, S)$ ratio). Since we can now obtain a single stereoisomer, there is no need for chromatographic separation. After the extraction, the $(R, S)$-product will be hydrolyzed into di-acid, then the di-acid will be reacted with thionyl chloride to prepare di-acid

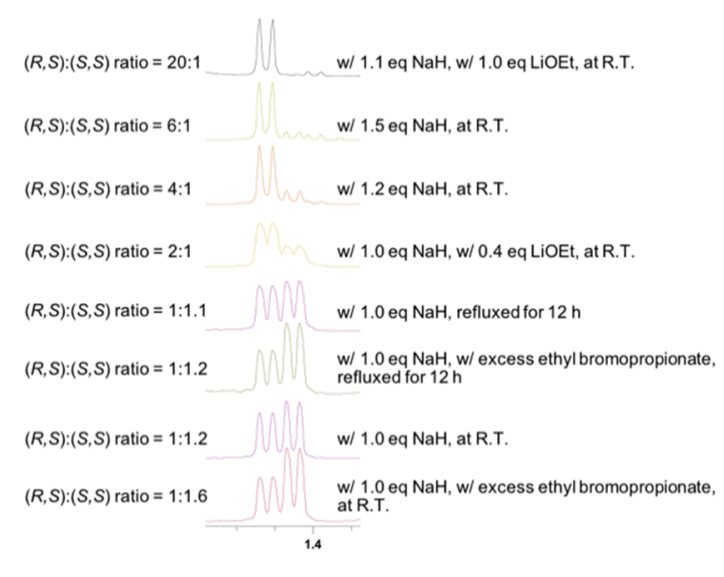


chloride intermediate, which then will be reacted with secondary amine to produce the final product. Only the final product will be purified using column chromatography to ensure its $>98 \%$ purity. The needed 2 $\mathrm{kg}$ of secondary amine starting material has not yet been delivered to ORNL; the estimated delivery date is February $3^{\text {rd }}$.

The starting material (3,6,9,15-tetraazabicyclo[9.3.1]pentadeca-1(15),11,13-triene) for the synthesis of DOTA-based ligand was delivered today, synthesis of the desired product will be initiated next week.

The Ir-catalyzed C-H borylation of methyl 6-(((2-(tert-butoxy)2-oxoethyl)amino)methyl)picolinate has been optimized, for full conversion $5 \mathrm{~mol} \%$ of the catalyst and 1.5 eq of $\mathrm{B}_{2} \mathrm{pin}_{2}$ are required (see the figure). Due to higher sensitivity of this substrate (product decomposes during the purification on silica gel column) it was not coupled with 2,6-

bis(dibromomethyl)pyridine or directly with acetylene due to the presence of unprotected amino group (reaction uses strong oxidant). Instead, the product was reacted with NaI, to convert the boron group into iodide. This conversion has been confirmed by ${ }^{1} \mathrm{H}$ NMR spectroscopy. After isolation, the product will be subjected to coupling with TMS acetylene and then coupled with 2,6-bis(dibromomethyl)pyridine. (S. Jansone-Popova)

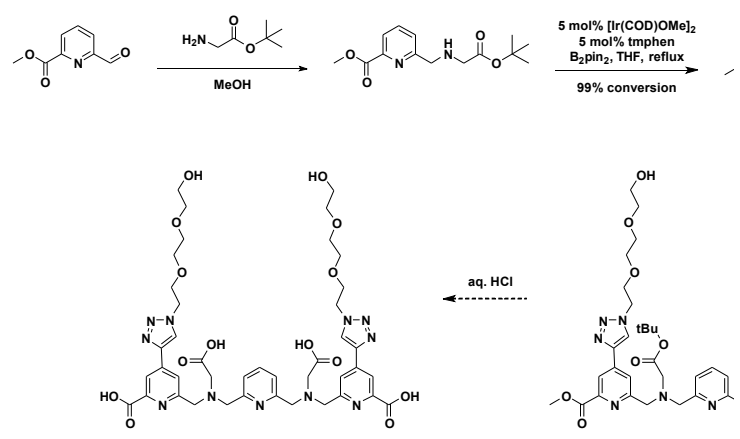

[PNNL] A manuscript titled, "Molar Absorptivities of U(VI), U(IV), and Pu(III) in Nitric Acid Solutions of Various Concentrations Relevant to Developing Nuclear Fuel Recycling Flowsheets," was completed and submitted to the peer reviewed Journal of Radioanalytical and Nuclear Chemistry. This paper reports values of molar absorptivities of $\mathrm{U}(\mathrm{VI}), \mathrm{U}(\mathrm{IV})$, and $\mathrm{Pu}(\mathrm{III})$ in nitric acid solutions of $0.5 \mathrm{M}$ to $4 \mathrm{M}$ concentrations and compares them with available technical literature data. The solution composition ranges covered are relevant to spectroscopic analysis of process streams encountered when recycling nuclear fuel through solvent extraction methods, such as the co-decontamination (CoDCon) flowsheet. The appropriate molar absorptivities were used to analyze aqueous grab samples from the CoDCon runs, yielding results in good agreement with independent analysis of the same samples by ICP-MS. (Sergey Sinkov, Gabriel Hall, and Gregg Lumetta)

\subsection{Advanced Waste Forms and Processes}

\subsubsection{Molten Salt Waste Forms}

[ANL] Long-term tests initiated in FY19 with two iron phosphate materials have been completed. The solution analyses indicate the build-up of dissolved phosphate does attenuate the dissolution rate. For example, the results of modified ASTM C1285 tests conducted with DPF5-280 and DPF5-366 at $90{ }^{\circ} \mathrm{C}$ and initial $S / V$ ratios of $500 \mathrm{~m}^{-1}$ are shown in Figure $3 \mathrm{a}$ and $1 \mathrm{~b}$, respectively, where the normalized mass 
loss based on the solution concentrations of $\mathrm{P}, \mathrm{Li}, \mathrm{Na}$, and $\mathrm{Cs}$ are plotted against the cumulative test duration. The curves show empirical power law fits with time dependencies of $\mathrm{NL}(\mathrm{Cs})=0.045 t^{0.54}$ for the test with DPF5-280 and NL(Cs) $=0.22 t^{0.36}$ for the test with DPF5-366. The relative releases of different elements from the two materials are different: releases of Cs and P from DPF5-280 are stoichiometric and $\mathrm{Li}$ is released preferentially, but releases of $\mathrm{Li}$ and $\mathrm{P}$ from DPF5-366 are stoichiometric and $\mathrm{Cs}$ and $\mathrm{Na}$ are released preferentially. This is attributed to different phase compositions: DPF5-280 is essentially a homogeneous iron phosphate glass, whereas DPF5-366 contains an abundance of lithium iron phosphate crystalline phase encapsulated in iron phosphate glass. It appears that the crystalline phase is more durable than the glass phase in DPF5-366, but $\mathrm{Cs}$ and $\mathrm{Na}$ are only present in the glass phase. The glass phase in DPF5-366 is less durable than the glass phase in DPF5-280. Modified ASTM C1285 tests conducted with DPF5-366 at $90{ }^{\circ} \mathrm{C}$ and initial $S / V$ ratios of $1500 \mathrm{~m}^{-1}$ showed the same behavior observed in Figure 3b. Analyses of the reacted solids are in progress. The available results for these and other tests will be included in progress report to be issued in early January. (W. Ebert)

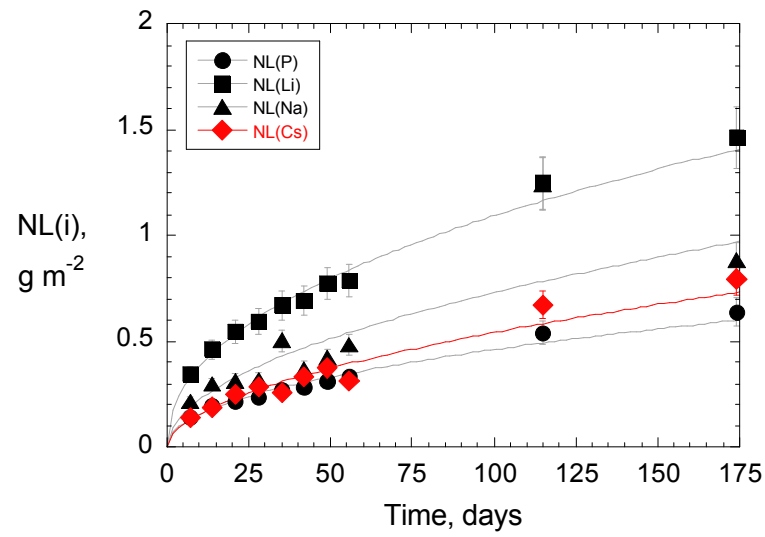

(a)

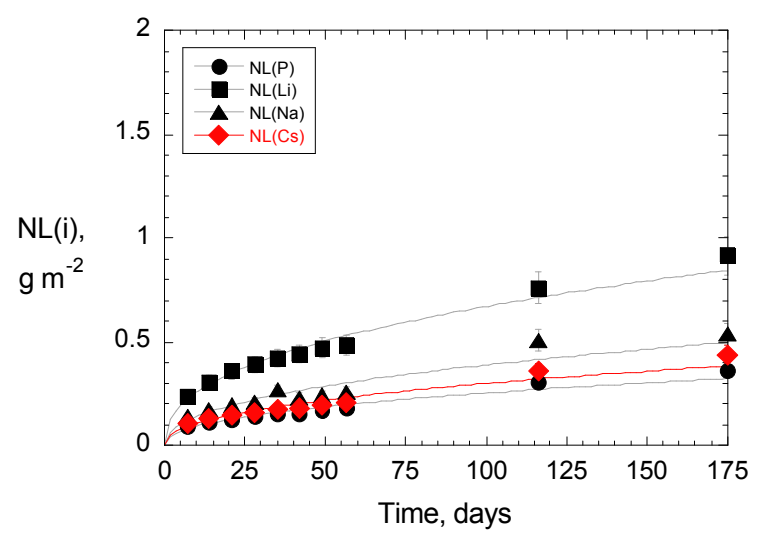

(b)

Figure 3. Results of modified ASTM C1285 tests with (a) DPF5-280 and (b) DPF5-366.

[PNNL] A paper was accepted for publication in Acta Crystallographica E on the synthesis of a new mixed alkaline earth powellite crystal titled: Kissinger, R.M., S. Chong, B.J. Riley, and J.V. Crum, "Synthesis and crystal structure of a mixed alkaline-earth powellite, $\mathrm{Ca}_{0.84} \mathrm{Sr}_{0.16} \mathrm{MoO}_{4}$," Acta Crystallographica E76, 121-124, https://doi.org/10.1107/S2056989019017092 (2020). (B. Riley)

\subsubsection{Mechanisms and Material Behavior}

[ANL] Test solutions from modified PCT were sampled after 269 days to assess the effect of the solution composition on triggering Stage 3 behavior. Stage 3 has not been triggered in tests at moderate $\mathrm{pH}$ values and some glasses have completely corroded in tests run at $\mathrm{pH}$ values higher than 12 . This shows the important role of the solution compositions besides the $\mathrm{pH}$. Samples of reacted solids are being analyzed. (W. Ebert)

[PNNL] PNNL worked with our Corning Inc. partner to produce next-generation International Simple Glass as defined by consensus at the last International Workshop on Long-Term Glass Corrosion. Produced by a continuous-ribbon process, the glasses are much more homogeneous, have a clearer appearance, and have fewer bubbles than the last version. Approximately 500 pounds will be shipped to PNNL in the next month for storage and distribution to collaborators worldwide. The melting process went so well that Corning Inc. was able to transition to the original ISG composition and produce 500 pounds of that composition as well. This is excellent, as the original 110-pound batch had been almost completely distributed to researchers for use as a baseline. These glasses should position the 
collaboration to reference their corrosion research to a common composition for the foreseeable future and highlights the buy-in of Corning as the corporate partner in the efforts to create an improved scientific basis for the corrosion of glass materials. (M. Asmussen)

\subsection{Electrochemical/Molten Salt Processing}

[ANL] Electrochemical tests in $\mathrm{LiCl}$ salts with different impurities are in progress to understand and quantify the effects on redox properties. (W. Ebert)

[ANL] Modifications to the electrochemical cell that will be used to demonstrate co-deposition on a solid cathode remain in progress. Slides are being prepared to discuss approach and status in a meeting with INL and DOE planned for January. (W. Ebert)

\subsection{Sigma Team - Off-Gas}

[INL] The activity "Support assessment of the off-gas system requirements/conceptual design for pyroprocessing of metallic UNF," that was started on schedule in October 2019 continued. INL reviewed an outline drafted by ORNL for a joint ORNL/INL report due August 31, 2020. A review of literature also continued to meet an ORNL Level 4 milestone due January 31, 2020, to "Identify pyroprocessing off-gas characteristics, isotopes of concern and gaseous concentrations (N. Soelberg)

[ORNL] The Level 3 milestone M3FT-20OR0301070314 titled, "Complete Phase 1B CH3I Tests," was completed and a draft report issued. A summary of that report is as follows:

Repeated observations by INL have confirmed the presence of elemental iodine $\left(\mathrm{I}_{2}\right)$ in the effluent of $\mathrm{AgZ}$ deep beds, despite the sole iodine species in the feed gas being methyl iodide $\left(\mathrm{CH}_{3} \mathrm{I}\right)$. The intent of the joint test plan was to identify key questions regarding the behavior of $\mathrm{CH}_{3} \mathrm{I}$ when adsorbed by $\mathrm{AgZ}$ and to ensure that previously observed INL data was validated by duplicate testing. Seven thin bed tests characterizing the adsorption of $\mathrm{CH}_{3} \mathrm{I}$ and $\mathrm{I}_{2}$ by $\mathrm{AgZ}$ and $\mathrm{NaZ}$ were performed. The first three tests examined the effects of $\mathrm{NO}_{\mathrm{X}}$ and $\mathrm{H}_{2} \mathrm{O}$ on $\mathrm{CH}_{3} \mathrm{I}$ adsorption by $\mathrm{AgZ}$ and found that a $43 \%$ reduction in iodine capacity occurred when $\mathrm{NO}_{\mathrm{X}}$ was present in the feed stream (as compared to $\mathrm{CH}_{3} \mathrm{I}$ adsorption from a dry air stream) and that a $23 \%$ reduction in iodine capacity occurred when both $\mathrm{NO}_{\mathrm{x}}$ and $\mathrm{H}_{2} \mathrm{O}$ were present in the feed stream. Four of these thin bed tests compared the adsorption of $\mathrm{I}_{2}$ and $\mathrm{CH}_{3} \mathrm{I}$ by $\mathrm{NaZ}$ and $\mathrm{AgZ}$. As expected, it was observed that adsorbed iodine was bound strongly to $\mathrm{AgZ}$ and was not removed during the purge phase of testing. This was in contrast to $\mathrm{I}_{2}$ and $\mathrm{CH}_{3} \mathrm{I}$ adsorption by NaZ, in which significant weight loss was seen during the purge phase of testing. It was noted that $\mathrm{NaZ}$ did retain some $\mathrm{CH}_{3} \mathrm{I}(33 \mathrm{mg} / \mathrm{g} \mathrm{I}-\mathrm{NaZ})$ under the test conditions chosen $\left(\mathrm{CH}_{3} \mathrm{I}\right.$ capacity of $\mathrm{AgZ}$ is $75 \mathrm{mg} / \mathrm{g} \mathrm{I}-\mathrm{AgZ}$.) (R. Jubin)

[ORNL] A review of the literature on ruthenium in used nuclear fuel dissolver off-gas and methods to trap the ruthenium was conducted to augment a prior review. The report documenting the finding of that review completed Level 3 milestone M3FT-20OR0301070311. This current review also provides recommendations on two or three trapping materials to be tested in future experiments. The following is a brief summary of the report.

Ruthenium appears to be transported in the dissolver off-gas system as volatile $\mathrm{RuO}_{4}$, nitrosyl ruthenium complex [e.g., $\mathrm{RuNO}\left(\mathrm{NO}_{3}\right)_{\mathrm{X}}\left(\mathrm{NO}_{2}\right)_{\mathrm{Y}}(\mathrm{OH})_{\mathrm{Z}}\left(\mathrm{H}_{2} \mathrm{O}\right)_{5-\mathrm{X}-\mathrm{Y}-\mathrm{Z}}$ ] salts, and particulate $\mathrm{RuO}_{2}$. Based on the limited information on physical properties, the $\mathrm{RuO}_{4}$ moves as a gas, and any combination of all three forms move as entrained particulate or aerosol in the dissolver off-gas. Three materials are recommended for testing. A high surface area polymer to trap $\mathrm{RuO}_{4}$ immediately downstream of the dissolver system condensers, where the temperature is below $25^{\circ} \mathrm{C}$, is recommended for testing. Reheating the off-gas to and maintaining the sorbent at temperatures around $90^{\circ} \mathrm{C}$ may be required. High surface stainless steel wool and quartz (or ceramic) wool are two other deposition surfaces that 
can operate at elevated temperatures (e.g., $150^{\circ} \mathrm{C}-300^{\circ} \mathrm{C}$ ) and should be tested. Microspherical forms may be preferred for ease of handling. Deposition of $\mathrm{RuO}_{4}$ is enhanced at elevated temperatures, and such temperatures are needed to decompose nitrosyl ruthenium nitrates that may be entrained in the gas phase. In all cases, the deposited form is expected to be $\mathrm{RuO}_{2}$. Because some of these materials are friable and $\mathrm{RuO}_{2}$ particulate can form, the traps should be backed-up with HEPA filters. (R. Jubin)

[ORNL] The literature review supporting the milestone to identify pyroprocessing off-gas characteristics, isotopes of concern and gaseous concentrations is on-going. A draft annotated outline of the report was prepared and discussed with INL personnel on December 17. The results of those discussions are reflected in the modified draft. (R. Jubin)

[ORNL] In December, two tests on the $\mathrm{I}_{2}-\mathrm{Ag}^{\circ} \mathrm{Z}$ test matrix were completed and a third is ongoing. FY20009 tested $25 \mathrm{ppm} \mathrm{I}_{2}$ loading at $135^{\circ} \mathrm{C}, 1 \% \mathrm{NO}, 1 \% \mathrm{NO}_{2}$, with a dry air stream: total loading was $48 \mathrm{mg} / \mathrm{g}$ sorbent. FY20-010 tested 25 ppm $\mathrm{I}_{2}$ loading at $165^{\circ} \mathrm{C}, 0 \% \mathrm{NO}, 1 \% \mathrm{NO}_{2}$, with a dry air stream: total loading was $50 \mathrm{mg} / \mathrm{g}$ sorbent. Currently, test FY20-013 is running to test $25 \mathrm{ppm} \mathrm{I}_{2}$ loading at $165^{\circ} \mathrm{C}, 1 \%$ $\mathrm{NO}, 1 \% \mathrm{NO}_{2}$, with a humid air stream. There are six tests remaining between the $\mathrm{I}_{2}-\mathrm{Ag}^{\circ} \mathrm{Z}$ and $\mathrm{CH}_{3} \mathrm{I}-\mathrm{Ag}^{\circ} \mathrm{Z}$ test matrices. (R. Jubin)

\subsection{Melter Demonstration}

[INL] The design/build contract was awarded for the furnace. The draft P\&ID was prepared for the melter system. Weekly team coordination meetings are held with PNNL, assembly designers and fabricators. (E. Nef)

[PNNL] The melter feed system design is in process and on schedule. Glass formulation and melter feed formulation to support testing is complete. Planning for melter and off-gas testing is in progress. (B. Riley)

\subsection{Material Recovery Pilot Plant}

[ORNL] Run 15 was done at a bed temperature of $200^{\circ} \mathrm{C}$ while flowing a mixture of $\mathrm{HCl}$ and $\mathrm{N}_{2}$. The coupon was "floating", unattached inside the fluidized bed, and it displayed a relatively uniform reaction along the entire surface of the coupon. This behavior is in sharp contrast to the behavior for the "fixed" coupons, where most of reaction occurred at the bottom of the coupon. The results were very similar to previous runs at $200^{\circ} \mathrm{C}$ without dilution. It can be speculated that the expected decrease in the hydrochlorination rate by dilution was counteracted by a higher average surface reaction rate due to the expansion of the bed resulting from the higher overall flow rate. (R. Jubin)

\subsection{Polishing and Solidification (Extraction, Conversion, Downblending)}

[INL] Using the PNNL peroxide precipitation method, the INL Uranium Polishing lab scale demonstration separated the uranium product from the mixer settler strip solution. The U3O8 product from the Calcination stage is gray brown in color with agglomeration. Solid samples have been pulled and will be transferred to the Analytical Lab after curtailment. The calcination program for the furnace was modified to drive the process to form UO3. Samples of dissolver liquid and mixer settler stages are also ready to be transferred to MFC for analysis. (C. Williams)

[INL] Members of the Pilot Scale Uranium Polishing demonstration team along with a member of the Operational Facility Management met with MPR. MPR is the proposed engineering firm to provide the cost estimate and preliminary design information for the Uranium Polishing Pilot Scale 
Demonstration. Questions and comments relative to the Functional and Operational Requirements (F\&OR's) were answered and productive discussions about solvent extraction took place. It was proposed that in early 2020, MPR personnel would come to the INL to see the proposed location and other ZIRCEX processes. (C. Williams)

[ORNL] ORNL technical support personnel met with INL Zircex/HALEU project leaders in December to discuss MDD design assumptions and plans for application to denitration of HALEU and conversion to a $\mathrm{U}_{3} \mathrm{O}_{8}$ product powder. For the MDD design, ORNL will provide a list of assumptions and a preliminary design in January 2020. INL will be responsible for design of the glove box to contain the MDD unit and off-gas treatment system and will provide the initial feed composition of the HALEU solution to be fed to the MDD. ORNL will provide a list of specific tests and data needed to enable the initial conceptual design by the end of March 2020. (R. Jubin)

\subsection{Transportation}

[PNNL] PNNL met with INL staff for a kickoff meeting of the INL Onsite Mobile Reactor Transportation and Disposition Planning. This meeting was held December $18^{\text {th }}$ at INL. (H. Adkins)

For more information on Material Recovery and Waste Forms Development contact Terry Todd (208) 526-3365 


\section{MPACT CAMPAIGN}

\subsection{Campaign Management}

\subsubsection{NTD \& Management Support}

[LANL] MPACT NTD (travel for DOE/NNSA) participated in the DOE/NNSA 810 review of JFCS activities for potential IAEA observation. 810 guidance is important to MPACT activities when developing MC\&A approaches where a fuel cycle technology may eventually be transferred to a foreign partner. Understanding and preparing for transition of domestic MC\&A to IAEA safeguards positions U.S. nuclear development for international activities. MPACT NTD (travel for DOE/NNSA) participated in the Dec 17-19, 2019 U.S.-Taiwan Joint Standing Committee on Civil Nuclear Cooperation. MPACT NTD discussed safeguards issues related to U.S.-flagged fuel in Taiwan with potential interest to $\mathrm{DOE} / \mathrm{NE}$.

\subsection{MRWFD/Advanced Nuclear Safeguards and Security Research}

\subsubsection{MSR Safeguards}

[ORNL] Interim report in review on the results of the dose assessment and on the preliminary signatures work, which lays the foundation for the L2 milestone task and collaboration with SNL. A system level model is being developed for a convection driven molten salt loop. The convection loop is under development for corrosion studies in various molten salts. The modeling will be compared with empirical data of flow rate and temperature of the molten salts; the model will not be considering the chemistry of the salt. Mike Dion and Louise Worrall assisted RMD with the submission of a Phase I SBIR LOI to develop detector technology to support safeguards measurements of MSRs. Details of the tasking for the proposed collaborative work were discussed. Ben Betzler and Louise Worrall participated in a video teleconference call with PSU to receive a progress update on the PSU NEUP project.

\subsubsection{Microcalorimetry Consulting}

[LANL] Work focused on testing multiplexing chips in SOFIA. Tests are expected to be completed and resume measurements of gamma spectra in January.

\subsection{Safeguards and Security Supporting Technologies - Echem}

\subsubsection{Microfluidic Sampler}

[ANL] Assembly of the Raman spectroscopy unit was completed. Glovebox assembly of the custom oven for the analytical-scale molten salt loop was started.

\subsubsection{Bubbler for Measuring Density and Depth of Molten Salt}

[INL] Preparations were made to start molten salt testing in January. Aqueous testing was performed. Equipment to create turbulent flow for aqueous MSR testing was designed and discussed.

\subsubsection{OR Voltammetry}

[INL] Continued to collect and analyze data from HFEF OR. 


\subsubsection{ER Voltammetry}

[ANL] An updated sensor has been constructed and is ready for shipment to INL. The new design possesses minor updates to ensure that possible vibrations within the HFEF environment do not distort the electroanalytical measurements. Documentation describing sensor assembly and operations has been written and is being readied for delivery to INL in January. It is expected that Milestone M2FT20AN040104041-ER will be completed on time.

\subsection{Safeguards and Security Milestone 2020 - Echem}

\subsubsection{Modeling and Simulation for Analysis of Safeguards Performance}

[ANL] Two recently reported sources of $\mathrm{AgCl}$ reference electrode data (Baghri et al., 2019; Yoon et al., 2019) were identified and a critical review performed in comparison with previously available data (Yang \& Hudson, 1959; Shirai et al., 2008). Analysis considered concentration range of measurements relative to commonly used reference electrode compositions (frequently 0.1 or $1 \mathrm{wt} \% \mathrm{AgCl}$ ). While the data from Shirai et al. covered a more applicable concentration range than that of Yang and Hudson, the newer data sets were found to be consistent with Yang and Hudson's measurements. Shirai et al.'s data for $\mathrm{E}^{\circ} \mathrm{AgCl}$ versus the $\mathrm{Cl}-\mid \mathrm{Cl} 2$ reference differed from the other research groups by $\sim 150 \mathrm{mV}$, which is significant when standard potentials for some actinide and/or rare earth pairs are separated by differences on the order of tens of millivolts. In light of the newer (i.e. 2019) data, it is concluded that the data from Shirai et al. should not be used as a basis for calculations performed with the DyER and AMPYRE codes at this time as it could lead to erroneous conclusions. A correlation derived by Ogawa (2010) from the Yang and Hudson data, and consistent with measurements by both Baghri et al. and Yoon et al., is preferred. Electrochemical parameters used in the DyER (electrorefiner) model to calculate mass flows have been adjusted in light of the new data. Results generated with the DyER and AMPYRE codes are being updated accordingly. This is considered a high priority as the electrochemical parameters in the models are aggregated from various literature sources. The reported measurements must be shifted from their specific concentration of $\mathrm{AgCl}$ reference electrode to a consistent scale. These parameters strongly affect the predicted elemental separations in electrochemical unit operations (electrorefiner, electrolysis, etc.) and, therefore, the overall distribution of accountable material in a reprocessing facility.

\subsubsection{Security Facility Models}

[SNL] The Security Model is being updated and a vulnerability analysis has been initiated.

For more information on MPACT contact Mike Browne at (505) 665-5056. 


\section{SYSTEMS ANALYSIS AND INTEGRATION (SA\&I) CAMPAIGN}

\subsection{Campaign Management}

[ANL, INL] Completed the FY 2019 Achievement Report for the Systems Analysis and Integration (SA\&I) Campaign. The report discussed the Campaign Mission, Objectives, and Key Deliverables, and provided representative highlights of the Campaign's work completed during the fiscal year.

\subsection{NUCLEAR ENERGY SYSTEM PERFORMANCE (NESP)}

\subsubsection{Technology Maturity \& Economic Performance Potential of Micro- reactors}

[ANL, BNL, INL, ORNL] Held a conference call to discuss the working plan and milestones for assessment of TSRA and economics of two micro reactor concepts, which include the selection of micro reactor concept, system/technology break-down, TSRA and cost estimations, vendor review and development report.

[ANL] A meeting with HolosGen LLC was held on December 17, and HolosGen LLC agreed to share the design information with the SA\&I campaign for the TSRA and cost assessment.

[ANL] Reviewing the literature on the costing methodologies for modular reactors. There are a number of important factors affecting cost that are not just scaling and eliminating components. The largest being the potential for significantly different indirect costs as a result of a much greater fraction of the work being done prior to the components being transported to the site with the extreme case being a complete working reactor being deliver to the site with minimal onsite work to bring online.

\subsubsection{Impacts of Foreign Energy Transition Policies}

[ANL] Continued collection of publicly available data on the impacts of energy policy changes in Korea, and Japan, which include the annual reports of utilities, electricity generation costs, energy sources, etc.

\subsubsection{Factors Impacting Nuclear Energy Share}

[ANL] Reviewed the collected literature on the sustainability of nuclear energy in future markets and policy environments from OECD/NEA, university, consulting companies, etc., and the information was categorized into "cost competitiveness" and "decarbonization".

\subsubsection{Re-use of Decommissioned Nuclear Assets}

[ORNL] The scope of work and approach was discussed and agree with ANL on a couple of calls during the past month.

\subsubsection{FCDP Development for Specific Advanced Reactors}

[ORNL] Resource has been found and allocated to this task. The early career professional is new to the Campaign and developing FCDPs and has therefore been spending some time getting up to speed with the previous FCDPs and approach to developing them. 


\subsubsection{Maintain/Update of Fuel Cycle Catalog}

[INL]. We continued to work with the SNL SharePoint team to diagnose problems they were having with SharePoint that were affecting entering data into the catalog, but not affecting the public Nuclear Fuel Cycle Catalog.

[SNL] We continued to monitor the performance of the public Nuclear Fuel Cycle Options Catalog to ensure that it functioned properly. Two problems were identified and corrected.

\subsubsection{TSRA Analysis for Fast Reactor Annular Fuel}

[BNL] Had initial discussion with the National Technical Director and several staff members of the Advanced Fuels Campaign (AFC) to review past efforts in this area and plan next steps on how to proceed with the current effort. Note that the focus of this task has been changed to "sodium-free fast reactor metallic fuels" to include other options being explored by the AFC.

\subsubsection{Transition Analysis Studies and Tools Development}

[ORNL] A one day meeting was held at ORNL to discuss the latest developments and needs for the next phase in Cyclus development and application. The meeting was attended by both the Cyclus developers (Paul Wilson, Wisconsin, and Katy Huff, UIUC) and a cross-section of users/potential users from the Campaign. Specific outcomes from the meeting included agreement that the goals of any future GUI should be ease usability of Cyclus, and to educate user to be expert user of Cyclus (without direct expert user help). However, a full GUI may not achieve these goals, since the user gains little insight into the 'inner workings' of Cyclus. Integration into the NEAMS workbench, where a hybrid interface of Integrated Development Environment (IDE) and fill-form GUI, was discussed as one potential solution. The future actions arising from the meeting included (1) ORNL developers to discuss NEAMS workbench integration, (2) ORNL to set up Cyclus integration in NEAMS workbench, (3) Cyclus developers to evaluate and produce a Cyclus a remote access communication tool.

[ANL] A manuscript was submitted to the journal Annals of Nuclear Energy based on the FY19 M2 report "Reassessing Methods to Close the Nuclear Fuel Cycle" INL/LTD-19-53401.

[ANL] Successfully enabled Dakota/DYMOND to run multiple scenarios simultaneously on UNIX systems to mass produce data needed for uncertainty quantification and sensitivity analyses. Initial modeling specifications for the control transition scenario for the sensitivity analyses were developed and distributed to other laboratory participants.

[SNL] We met with Yarden Livnat of the University of Utah Scientific Computing and Imaging Institute to discuss potential ways of improving the visualization and story-telling capabilities of the transition analysis tools.

[ORNL] The development, testing, and evaluation of the Cyclus prototype GUI continued in readiness for the above meeting at ORNL. A demo of the approach and tool was prepared and presented at the meeting. Work also included the development of a reactor module in Cyclus that depletes fuel using the transition matrix binary files from SCALE using ORIGEN, hence providing a direct coupling of Cyclus with ORIGEN. 


\subsection{ECONOMIC AND MARKET ANALYSIS FOR NUCLEAR ENERGY SYSTEMS (EMANES)}

\subsubsection{Improvement of ACCERT Algorithm}

[ANL] Continued collecting data on the Landmark pyroprocessing facility.

[ANL] Reviewing the literature on indirect cost models. Identified an optimistic estimate of the indirect costs of NuScale 12 pack compared to the median experience and best estimation of PWR. To get better understanding of breakdown indirect costs, additional investigation is needed.

[ANL] Reviewing the literature on factory fabrication cost mode. The potential benefits are significant, but trying to better understand the transitional nature of the cost that could be very significant if large investments in new fabrication facilities are required.

[ANL] Reviewing the literature on modular fabrication cost model. There needs to be a substantial change in how the indirect costs are calculated compared to a traditional large stick-built plant. It is in many ways just a different model. It is likely that much of the current assumptions are highly optimistic, so there is a need to revisit the underlying assumptions and better understand the likely processes.

[INL] INL staff coordinated with ANL staff assigned to this activity and engaged in discussion to determine cost benchmarking case study. A non-reactor, fuel cycle case study is needed whereby the algorithms in ACCERT can be evaluated for gaps and performance in cost estimating non-reactor fuel cycle costs. Several possible case studies were suggested and are currently evaluating to determine data sufficiency.

\subsubsection{Daily Market Analysis of Load Following and Storage Impacts}

[ANL] Meeting with ANL Energy System (ES) division grid modeling experts was held on December 6 to finalize their support to the SA\&I activity and daily market analysis. Also obtained a high performance computer account to gain access to the ES A-LEAF code for daily electricity market analysis.

[BNL] Participated in monthly telecom led by ANL. Additionally, the information on time slicing in the MARKAL documentation is not too clear. Test runs with increasing the number of slices were performed to clarify that there does not seem to be a hardcoded limit in the code on the number of time slices permitted.

\subsubsection{Cost Basis Report Enhancements}

[ANL] The entire cost basis report was reviewed to understand the complete content and structure. A proposed approach and structure was developed and discussed with the group. There was general agreement on the structure of the report. This has been further refined.

[ANL] Williams (ANL-Contractor) is continuing his work on updating and revising fuel fabrication cost modules in the Cost Basis Report. He provided a summary of all unpublished work and plans for 2020 deliverables.

[INL] INL staff continued to collaborate with ANL staff on plans and implementation to updates to the CBR. INL staff started a review of the cost escalating data in a revised spreadsheet. 


\subsubsection{Regional and Global Analysis}

[PNNL] Began drafting paper on the role and value of nuclear energy for addressing climate change for journal article submission. Developed framework for the paper but revised GCAM scenario results necessary to reflect recent changes to the global energy system.

[PNNL] Participated in Daily Market Analysis planning meeting and discussions. Contributed to OECD/NEA expert group report on Advanced Reactor Systems and Future Energy Market Needs.

\subsubsection{Lessons-Learned from LWR Deployment History}

[INL, BNL] INL staff met with staff from BNL and post-doc collaborator working at INL. Discussed plan for the report and preliminary data findings from literature review. The team set up a schedule for recurring, bi-weekly telecons where status and findings would be discussed and writing assignments arranged.

[BNL] Provided additional documents to the project SharePoint library.

\subsubsection{Adaptation of OR-SAGE for NES Analysis}

[ORNL] Planning work is underway to produce the next evolution of the OR-SAGE tool. This has included conference calls with potential end users e.g., Envoy Public Labs (recommended by the GAIN initiative), and university researchers working in GIS related nuclear topics.

For more information on Systems Analysis and Integration contact Temitope Taiwo (630) 252-1387. 


\section{JOINT FUEL CYCLE STUDY ACTIVITIES}

Two Level 2 milestones were completed:

- Completed electrorefining of the first batch of IFSF-Stored LWR fuel, and

- Developed Post Irradiation Examination Plan for IRT test rodlets.

The third and fourth $4 \mathrm{~kg}$-scale oxide reduction system tests with irradiated LWR fuel were completed. Initial data for this tests indicated $>90 \%$ conversion of oxide fuel to metal in the first pass reduction.

The second $4 \mathrm{~kg}$-scale electrorefining test with irradiated LWR fuel was completed. This test used irradiated LWR fuel previously reduced in the oxide reduction system. Tests confirmed initial results of $>90 \%$ conversion of oxide fuel to metal. The third 4-kg electrorefining test was initiated.

An off-gas capture experiment in HFEF was completed using stakeholder provided filter media and irradiated LWR fuel. Results demonstrated successful removal of cesium and iodine from the off-gas stream.

The annual JFCS stakeholder progress report was delivered to program stakeholders.

Several stakeholder meetings were hosted for continued collaboration, including

- ERWG meeting in Daejeon November 19 - 20,

- Experts meeting on Electrorefining at INL, November 5-7, and

- Experts meeting on Fuel Cycle Systems at INL, November 12 - 13.

Visiting experts from KAERI were hosted for economic analysis and off-gas capture.

For more information on Joint Fuel Cycle Studies Activities contact Ken Marsden (208) 533-7864. 


\section{AFCI-HQ PROGRAM SUPPORT}

Site: University Research Alliance at West Texas A\&M University in Canyon TX, and the following universities: Ohio State University, University of Tennessee at Knoxville, Georgia Institute of Technology, University of Idaho, Colorado School of Mines, University of South Carolina, Florida State University, Northwestern University, Clemson University, North Carolina State University, University of Utah, University of Chicago, Columbia University, University of Toledo, and other universities.

Universities engaged in Nuclear Technology research via URA programs since 2001:

Boise State University

Boston College

Clemson University

Colorado School of Mines

Columbia University

Georgia Institute of Technology

Georgetown University

Idaho State University

Florida International University

Florida State University

Kansas State University

Massachusetts Institute of Technology

Missouri University of Science and

Technology

North Carolina State University

Northern Illinois University

Northwestern University

Ohio State University

Oregon State University

Pennsylvania State University

Purdue University

Rensselaer Polytechnic Institute

Rutgers University

Texas A\&M University

University of Arkansas
University of California at Berkeley

University of California at Santa Barbara

University of California at Davis

University of Chicago

University of Cincinnati

University of Florida

University of Idaho

University of Illinois at Urbana-Champaign

University of Michigan

University of Missouri

University of Nevada at Las Vegas

University of New Mexico

University of North Texas

University of Notre Dame

University of Ohio

University of South Carolina

University of Tennessee at Knoxville

University of Texas at Austin

University of Toledo

University of Utah

University of Virginia

University of Wisconsin

Vanderbilt University

Virginia Commonwealth University

Washington State University 


\subsection{Innovations in Nuclear Technology R\&D Awards}

\subsubsection{University Programs}

\subsubsection{Summary Report}

University Research Alliance continued processing reimbursements for the 2019 Innovations Awards winners' travel expenses for the ANS Winter Meeting in November.

University Research Alliance continued to prepare materials for the 2020 Innovations Awards.

University Research Alliance continued preparations for the 2020 Innovators' Forum, tentatively scheduled for May 2020.

University Research Alliance continued to improve the email distribution list in preparation for the 2020 Innovations Awards.

For more information on the University Research Alliance contact Cathy Dixon (806) 651-3401. 